\title{
Secondary health conditions and their impact on the wellbeing of people with spinal cord injury, South Africa: Patients perspective.
}

SONTI PILUSA ( $\sim$ Sonti.pilusa@wits.ac.za )

University of the Witwatersrand Faculty of Health Sciences https://orcid.org/0000-0003-0606-9669

Myezwa Hellen

University of the Witwatersrand

Potterton Joanne

University of the Witwatersrand

Research article

Keywords: secondary health conditions, secondary complications, spinal cord injury, prevention strategies, South Africa

Posted Date: October 29th, 2019

DOI: https://doi.org/10.21203/rs.2.16532/v1

License: (c) (i) This work is licensed under a Creative Commons Attribution 4.0 International License. Read Full License 


\section{Abstract}

Background Long-term rehabilitation that includes preventive care for people with spinal cord injury is key to promoting health. There is evidence that secondary health conditions (SHCs) are prevalent complications across the continuum of care for people with spinal cord injury, leading to recurrent hospitalization and poor quality of life. In order to develop a context-based prevention model of care and strategies in South Africa, there is a need to understand the lived experiences of people with spinal cord injury (SCl).

Aim To describe people with spinal cord injury's experiences of secondary health conditions and the impact these have on their wellbeing.

Methods A qualitative descriptive design using semi-structured interviews was adopted. Purposive sampling was used to collect data from 17 participants with $\mathrm{SCl}$ who attend outpatient medical care at a tertiary rehabilitation hospital in Gauteng, South Africa. Primary data were collected from August 2018July 2019. All interviews were transcribed verbatim and analysed using a thematic analysis approach.

Results People with spinal cord injury experience a range of secondary health conditions, of which pain, bowel and bladder issues were the most common. The presence of SHCs had an impact on the psychological, physical and social wellbeing of the participants.

Conclusion There is a need for prevention interventions (health education and screening) for SHCs throughout the continuum of care and at all levels of prevention. Further research on factors influencing the prevention and management of SHCs is needed.

\section{Background}

Spinal cord injury ( $\mathrm{SCl}$ ) is a physical disability caused by a complete or incomplete lesion in the spine either due to trauma (gunshot, vehicle accidents, sports-related injuries and falls) or diseases like HIV, cancer, arthritis, cancer, and tuberculosis (TB) $(1-3)$. The prevalence of SCl was estimated to range from 698-827 per million population among high-income countries and 220-519 per million people in lowincome countries (4). The disparity is probably due to epidemiological data on disability from low-income countries not being monitored $(3,5,6)$. Surveillance data indicate an incidence of spinal cord injury of 75.6 people per million in South Africa, mainly caused by injury in the form of assault (59.3\%) motor vehicle accidents (26.3\%) (7). Although the incidence of SCI seems low, the three main causes of SCI namely HIV, TB and injuries, contribute significantly to the burden of disease in South Africa even if there is limited research on these causes $(8,9)$. Given that there is no cure for $\mathrm{SCl}$, research on the health needs and care gaps for this group of people is imperative as advocated by global and national initiatives such as the Rehabilitation 2030 and Sustainable Development Goal number 3 " healthy lives and promotion of the well-being of all" $(10,11)$. 
Previous studies have shown that preventable secondary health conditions are common in people with $\mathrm{SCl}$. Secondary health conditions (SHCs) are complications that can occur post-SCl throughout the continuum of care. These complications are not directly caused by the spinal cord injury but are related to living with a disability $(12,13)$. During the acute hospital phase, the prevalence of SHCs ranges between $59 \%-78 \%(14,15)$. Whilst the prevalence of SHCs post-acute phase seems to be even higher $(88 \%-100 \%)$ $(14,16,17)$. Also, there is evidence that SHCs co-exist, with clustering of multiple SHCs (18). What this all means is that throughout the continuum there is a need for holistic and targeted prevention strategies such as health education, screening and prevention protocols to minimize the occurrence of these secondary health conditions and their impact on the wellbeing of people living with SCl.

The impact of secondary health conditions is the main issue patients with $\mathrm{SCl}$ complain about and must not be underestimated. Secondary health conditions have been reported to limit the quality of life $(17,19)$; health (20); participation at work (21); social life (22) and to be a barrier to self-management (23). There are many studies that have explored lived experiences of $\mathrm{SCl}(21,24,25)$ and unmet care needs $(24-26)$. However, the focus on the experiences of SHCs and their impact on wellbeing is limited. Callaway et al (21) conducted a pilot study exploring lived experiences of secondary health conditions in Australia to inform the National Disability Insurance Scheme. The study reported a range of secondary health conditions experienced by people with $\mathrm{SCl}$ and their impact in limiting participation. Unfortunately, we cannot generalise the findings of Callaway's study to South Africa because the context is not the same. There is a need for context-based exploration of people with $\mathrm{SCl}$ experiences of SHCs and their impact on their well-being.

In South Africa, research on the experiences of SHCs in people with $\mathrm{SCl}$ across the continuum of care is scarce. A study focusing on patients with traumatic SCl found that $50 \%$ of the participants had one or more SHCs (27). The most common SHCs reported in the study were pressure ulcers, pulmonary complications and urinary tract infection. This study focused only on patients with traumatic $\mathrm{SCl}$ during acute hospital phase. On the same note, Mashola and Mothabeng,(28) reported the association between health behaviour, SHCs and quality of life (QOL) in people with $\mathrm{SCl}$ discharged from a private rehabilitation hospital. The top three SHCs that had a significant effect on activity and independence were chronic pain (47\%), spasms (36\%) and joint and muscle pain (22\%). The presence of SHCs affected neuro-musculoskeletal health behaviour and the presence of chronic pain affected health and QOL. The majority of those with significant pain reported needing medical treatment to function in their daily life. Even though the results of the study are informative, the study represents a small population that supposedly has access to health insurance to cover high private health care costs. The reality in South Africa is that the majority (84\%) of South Africa's population don't have access to health insurance so they depend on the already strained public health system sector (29). Therefore, research on patients with $\mathrm{SCl}$ accessing public health care system in South Africa is imperitive, to understand their illness journey and care needs.

Health providers and patients see illness through different lenses. Kleinman's' explanatory model of illness states that views on illness are shaped by how people perceive the causes, symptoms, severity, 
expected consequences, appropriate treatment, anticipated outcomes, experiences related to the illness and coping mechanisms (30). If we are to fully understand the journey of people living with spinal cord injury, the complications they experience and their impact, we need to listen to patients' narratives of their experiences. Therefore, the objective of this study is to describe the experiences of SHC among people with spinal cord injury and the impact of SHC on their wellbeing.

\section{Methods}

\section{Study setting}

The study was undertaken at a public tertiary rehabilitation hospital in South Africa. The hospital has 79 beds offering rehabilitation services to patients with stroke, spinal cord injury, amputation, and head injuries to achieve their highest functional ability through therapy, education programmes, peer support and work-oriented visits. The disciplines available include occupational therapy, physiotherapy; speech therapy, dietetics, social work and psychology. The outpatient (OPD) services include doctor consultation; wound care management and collection of repeat medication and consumables; wheelchair seating clinic; individual therapy and wheelchair repairs; testing for HIV and non-communicable diseases. This rehabilitation hospital caters for the patients from other provinces due to lack of tertiary hospitals in those provinces.

\section{Study Population}

The key-informants were patients with $\mathrm{SCl}$ who attend outpatient medical care at the rehabilitation hospital once every three months. The inclusion criteria for the patients were a diagnosis of spinal cord injury, patients 18 years and above and must be a patient at the tertiary rehabilitation hospital. The key informants were recruited using purposive sampling.

\section{Data collection}

A qualitative descriptive design approach was used to give clarity and deeper understanding of the phenomenon of experiences of SHC among people with spinal cord injury and the impact of SHC on wellbeing (31). Semi-structured interviews were conducted using an interview guide that was developed, informed by literature on possible secondary health conditions which people with spinal cord injury experience. Part $A$ of the interview guide included questions on sociodemographic information including age, sex, and injury date, cause of injury, level of the lesion, occupation, use of an assistive device for mobility and marital status. Part B of the interview guide included broad questions with probes on spinal cord injury and experiences of secondary health conditions. The interview guide was piloted with a researcher experienced in qualitative methods. Prior to the interview, written informed consent for the interviews and audio recordings was obtained. Semi-structured interviews lasting approximately 50 minutes were conducted by the principal researcher in the language the participant was comfortable in and the interviews continued until data saturation was reached. All the interviews were audio-recorded and transcribed verbatim for data analysis. Data were collected between June 2018 and July 2019. 
In total, 17 interviews were conducted. The interviews were transcribed verbatim and the eleven interviews conducted in IsiZulu and Setswana were transcribed and then translated to English. All the transcripts were stored in a Microsoft Word document file. All the transcripts were read and spelling errors and mistranslation were removed prior to analysis. All the transcript were exported to MAXQDA version 2018.1 for analysis. Using thematic analysis coding was done inductively and deductively (32). One interview transcript was coded and a codebook was developed with the co-authors which was used for all the transcripts. Categorizing the codes was done both manually and using MAXQDA version 2018.1. Categorizing of the codes was done manually with the co-authors to identify the themes related to the study objectives. Recoding was conducted by the principal investigator and the results were compared.

Rigor

To ensure the trustworthiness of data the following strategies were be conducted (33). All the interviews were audio-recorded and debriefing sessions were conducted to discuss the research process, findings and data analysis with the co-authors with experience in qualitative research design. For transferability, the context and the demographic data of the participants were explained in detail. To ensure dependability a detailed description of the data collection, analysis and interpretation were outlined and code-recode procedure was employed- coding of a segment of data in two separate sessions and the results compared. To improve inter-coder reliability, a public health specialist with experience in health promotion and qualitative data analysis coded one transcript and the categories were compared.

\section{Results}

Characteristics of the participants

Seventeen patients with spinal cord injury were interviewed and the demographic information of the patients is presented in Table 1. The mean age of the participants was $44.7 \pm 13$ years with the age range of $27-72$ and the majority were male $14(82 \%)$. The main cause of spinal cord injury was motor vehicle accidents $7(41 \%)$ and the mean duration since injury was $9 \pm 7$ years. Only $6(35 \%)$ of the participants were married and $14(82 \%)$ were using a wheelchair for mobility.

Table 1: Demographic information for patients with spinal cord injury $(n=17)$

Age in years

$44.8 \pm 13.6$

(Mean, SD)

Age range (years)

27-72

Gender

n (\%)

Female

3(18) 
Male

Currently employed

Marital status

Single

Married

Time since injury (range in years)

(Mean, SD )

Cause of injury

Trauma

$14(82)$

Motor vehicle accident

Fall

Gunshot

Non trauma

TB spine

Tumour

Vitamin B deficiency

Type of SCI

Paraplegia

Quadriplegia

Hemiplegia

Completeness of the injury

Complete

Incomplete

\section{Assistive devices}

Wheelchair

Walking aid

None
$7(41)$

$3(18)$

$4(23)$

The study aimed to describe experiences of SHC among people with spinal cord injury and the impact of $\mathrm{SHC}$ on their wellbeing. The three themes that emerged from the qualitative data analysis were the "range of secondary health conditions experienced"; "co-occurrence of secondary health conditions" and the 
"impact of secondary health conditions on wellbeing". The range of secondary health conditions is presented in Table 2 followed by the qualitative narrative of the top two common secondary health conditions, co-occurrence of secondary health conditions and the impact of SHC on wellbeing.

Range of secondary health conditions experienced

Participants reported a range of secondary health conditions across the continuum of care, some SHCs occurring during the acute hospital phase and some in the post-discharge rehabilitation phase. The secondary health conditions experienced included pain; bowel and bladder problems; pressure sores; spasms; psychological problems (depression \& worry); injuries; contractures; osteoporosis; respiratory problems; sleep disturbance; sexual problems and fatigue (presented in Table 2). The most common secondary health conditions were pain, depression and bowel and bladder problems.

\section{Table 2: Range of secondary health conditions experienced $n=17$}




\begin{tabular}{|c|c|c|}
\hline \multicolumn{2}{|c|}{ Secondary health condition } & $\mathrm{n}(\%)$ \\
\hline \multicolumn{2}{|l|}{ Pain } & $16(94)$ \\
\hline \multirow[t]{4}{*}{ Bladder problems } & Incontinence & $16(94)$ \\
\hline & Urinary tract infection & $4(24)$ \\
\hline & Spastic bladder & $2(12)$ \\
\hline & Kidney stones & $1(6)$ \\
\hline \multirow[t]{4}{*}{ Bowel problems } & Incontinence & $11(65)$ \\
\hline & Constipation & $6(35)$ \\
\hline & Rectal prolapse & $1(6)$ \\
\hline & Bloating & $1(6)$ \\
\hline \multicolumn{2}{|c|}{ Psychological problems (depression, worry, stress) } & $12(71)$ \\
\hline \multicolumn{2}{|l|}{ Pressure sores } & $10(59)$ \\
\hline \multicolumn{2}{|l|}{ Spasms } & $9(53)$ \\
\hline \multicolumn{2}{|l|}{ Contractures } & $3(18)$ \\
\hline \multirow[t]{3}{*}{ Injuries } & Burns & $9(53)$ \\
\hline & Fractures & $4(24)$ \\
\hline & Falls & $8(47)$ \\
\hline \multicolumn{2}{|l|}{ Sexual issues } & $7(41)$ \\
\hline \multicolumn{2}{|l|}{ Sleep disturbances } & $6(35)$ \\
\hline \multicolumn{2}{|l|}{ Fatigue } & $4(24)$ \\
\hline \multirow[t]{3}{*}{ Skeletal problems } & Osteoporosis & $2(12)$ \\
\hline & Arthritis & $1(6)$ \\
\hline & Myositis ossificans & $1(6)$ \\
\hline \multicolumn{2}{|c|}{ Respiratory problems } & $1(6)$ \\
\hline
\end{tabular}

Further probing revealed the nuanced experience of the common secondary conditions as shown in the qualitative results. The two most common secondary health conditions experienced by patients with spinal cord injuries are discussed below.

\section{Pain}


Ninety four percent of the participants experienced pain. The dimensions of pain expressed were the type, intensity, location and factors that worsened and eased the pain. Participants experienced "sharp burning pain", joint pains and muscle pains. For some participants, the pain symptom was constant whilst a few had intermittent pain. Pain intensity ranged from unbearable to manageable and it was worsened by spasms and cold weather.

"Out of 10 my pain level is always 7.5 , sometimes 9 , sometimes 10 . That is the biggest, biggest challenge."' Female paraplegic 61 years.

"I have constant pain. I have pain daily ...if the pain can stop I will know that I'm no longer alive" Male paraplegic 44 years.

Pain symptom was mostly managed by pain medication (tramadol) prescribed at the hospital. In addition, to ease the pain, some participants exercised, practised mindfulness, "ignored the pain", accepted pain as part of their lives and kept busy so that they don't focus on the pain.

\section{Bowel and Bladder problems}

Participants described bowel and bladder problems experienced and how they manage them. For bowel problems, participants experienced incontinence, diarrhoea and constipation. To manage bowel movements most patients used Coloplast, and to relieve constipation medication (Dulcolax) was used. Bladder problems included urinary tract infection, urine leaking and few had bladder stones. Participants expressed fear of accidentally leaking urine leading to restriction of water consumption and increasing the risk of urinary tract infection.

"I don't drink a lot of water because I feel, I can't keep urine for a long time"

Male paraplegic 39 years.

And another thing is that going to the bathroom, you can't feel whether you need to urinate or to do number 2, that's another stressful issue"

Male paraplegia 38 years

From the data analysis, there were patterns ofco-occurrences of secondary health conditions. The cooccurrence of secondary health conditions noted was for osteoporotic bones and fractures; spasms and pain; spasm and sleep disturbance illustrated in Table 3.

\section{Table 3: Co-occurrence of secondary health conditions}




\begin{tabular}{|c|c|c|}
\hline Themes & Category & Quote \\
\hline $\begin{array}{l}\text { Co- } \\
\text { occurrence } \\
\text { of } \\
\text { Secondary } \\
\text { health } \\
\text { conditions }\end{array}$ & $\begin{array}{l}\text { Some SHCs } \\
\text { cluster/coexist }\end{array}$ & $\begin{array}{l}\text { I am now } 30 \text { years (living with spinal cord injury), } \\
\text { sometimes, like not sleeping at night and you have spasms } \\
\text { and your legs are kicking and you can't sleep. It's very } \\
\text { demoralising when your foot goes like this all night, and } \\
\text { just when you fall asleep, it feels like somebody is just } \\
\text { giving you a pull in your foot like that. So you can't sleep," } \\
\text { Male quadriplegic } 50 \text { years. }\end{array}$ \\
\hline
\end{tabular}

The impact of SHCs on wellbeing is illustrated in Table 4 using pain as an example

\section{Table 4: Impact of secondary health conditions on wellbeing.}

The presence of a secondary health condition had an impact on the psychological, physical and social wellbeing of the participants.

\begin{tabular}{|c|c|c|}
\hline Themes & Category & Quote \\
\hline \multirow[t]{3}{*}{$\begin{array}{l}\text { Impact of } \\
\text { Secondary } \\
\text { health } \\
\text { conditions on } \\
\text { wellbeing }\end{array}$} & $\begin{array}{l}\text { Psychological } \\
\text { wellbeing }\end{array}$ & $\begin{array}{l}\text { "Phew, my neuropathic pain is the reason why I was in, } \\
\text { the primary reason why I was always thinking about } \\
\text { suicide, is that pain. Out of } 10 \text { my pain level is always 7.5, } \\
\text { sometimes 9, sometimes } 10 \text {. That is the biggest, biggest } \\
\text { challenge" } \\
\text { Female paraplegic 61years. }\end{array}$ \\
\hline & $\begin{array}{l}\text { Physical } \\
\text { wellbeing }\end{array}$ & $\begin{array}{l}\text { "Pain is on the back on the spine. So I am back on the } \\
\text { wheelchair, some days the pain is unbearable, I can't hold } \\
\text { my crutches..." Female paraplegic } 38 \text { years. }\end{array}$ \\
\hline & $\begin{array}{l}\text { Social } \\
\text { wellbeing }\end{array}$ & $\begin{array}{l}\text { "The issue of pains, when you at work you won't be happy } \\
\text { when you have pain even... even if people make jokes } \\
\text { when the pain comes you won't be happy.. it stresses me" } \\
\text { Female paraplegic } 27 \text { years }\end{array}$ \\
\hline
\end{tabular}

\section{Discussion}


The purpose of this study was to explore and describe experiences people with spinal cord injury have with secondary health conditions and the impact of SHC on their wellbeing. Using a descriptive qualitative approach three themes emerged, the range of secondary health conditions experienced, the cooccurrences of secondary health conditions and the impact of secondary health conditions on the wellbeing. Patients with $\mathrm{SCl}$ experienced a range of SHCs in agreement with previous studies on secondary health conditions occurring throughout the continuum of care, during inpatient hospital, $(14,15,27)$ and post-hospital discharge $(17,21,34)$. In comparison to local studies, the findings of this study are not surprising. Joseph et al (27) reported $50.3 \%$ of patients with $\mathrm{SCl}$ in acute tertiary care in Cape Town, had one or more secondary health conditions. Whilst Mashola and Mothabeng (28) reported a range of SHCs experienced by patients with $\mathrm{SCl}$ from a private rehabilitation hospital. There is a need for longitudinal research tracking the occurrence of SHCs and factors influencing the prevention of these $\mathrm{SHCs}$ in people with $\mathrm{SCl}$ throughout the continuum of care.

Similar to other studies on SHCs, pain, bowel and bladder problems were the most common complications experienced by people with $\mathrm{SCl}(21,25)$. A study by Piatt et al $(35)$ described problematic secondary health conditions among adults with $\mathrm{SCl}$ and the impact on social participation and daily life. Pain and bowel regulation issues were ranked in the top problematic complications affecting social participation and daily life regardless of the majority of the participants having had attended a wellness programme (35). Similar findings were reported in a study by Fuseini, Aniteye and Alhassan, (36) on the experiences of spinal cord injury in Ghana. The experience of SCl included physical effects such as pain, bowel and bladder problems and pressure sores. Even though the study used different terminology to describe "physical effects of SCl", in essence, these are the complications that can occur post-SCI collectively termed secondary health conditions. The presence of such diverse descriptions indicates the need to establish clearer terminology for secondary health conditions for research, planning and setting priorities for care for people with SCl.

There was co-occurrence of some of the secondary health conditions (Figure 1: Co-occurrence of secondary health conditions). For example spasms at night can disturb sleep patterns, leading to fatigue. Similar findings were reported by Brinkhof et al (18) indicating that some secondary health conditions cluster together such as pain and spasticity. There is a need for research to understand in detail the cooccurrence of SHCs and how they influence each other. The understanding of clustering of SHCs can be used to inform intervention strategies to not only focus on one SHC. In terms of clinical practice, clinicians must be aware of SHCs that coexist and screen for them during medical check-ups.

SHCs were found to have a negative impact on the psychological, physical and social well-being of patients with $\mathrm{SCl}$. Pain symptom was used to illustrate the impact of SHCs on the wellbeing. Pain in the life of a person with a disability such as $\mathrm{SCl}$ is a common symptom in all the phases of care. The reported prevalence range between $34 \%-92 \%(16,18,35,37)$ with the type of pain (neuropathic or joint or muscle pain) influenced by the level of the lesion and the duration of the spinal cord injury (38). The presence of pain at times is related to the presence of other SHCs such as spasticity, pressure sore, contractures, urinary tract infection $(21,37)$. Pain has an impact on many dimensions of health namely 
quality of life (17,37); health (20); occupation (21); social life (22) and is a barrier to self-management (23). In agreement with the literature, the participants in this study expressed how pain made them worry, affected their sleep and mobility and limited their social participation. Clearly, focusing only on the health problem presence of pain and quantifying pain doesn't fully give a picture of the illness. To fully understand illness and health outcomes we need to focus on the impact of illness on the broader domains of health such as functional activities and participation in the community. For that reason, clinicians should be encouraged to use biopsychosocial framework such as the International Classification of Functioning, Disability and Health for assessment and treatment purposed throughout the rehabilitation process to fully capture the picture of illness and health.

\section{Conclusions}

This study aimed to describe people with spinal cord injury's experiences of secondary health conditions and the impact these have on their wellbeing. People with $\mathrm{SCl}$ experience a range of SHCs across the journey of care which has an impact on their psychological, physical and social wellbeing. The most commonly reported SHCs were pain, bowel and bladder problems. Given that SCl is a permanent disability, requiring a holistic approach to care throughout a continuum there is a need to strengthen prevention care within the rehabilitation process. Understanding the patients with $\mathrm{SCl}$ experiences of SHCs and their impact can be used to strengthen patient-oriented approaches to care. In addition, the findings of this study also highlight the need to encourage screening for SHCs during the medical checkup and develop targeted health education programmes that will empower patients with $\mathrm{SCl}$ to prevent the occurrence SHCs or minimize their impact on wellbeing.

\section{Implications}

In order to develop a context-based prevention model of care for SHC which encourage patient-oriented rehabilitation care, an understanding of lived experiences of secondary complications related to $\mathrm{SCl}$ is imperative. This study has added to the body of knowledge on secondary complications post-SCI. The study results will help clinicians understand priority health problems in patients with $\mathrm{SCl}$ and inform rehabilitation care throughout the continuum.

\section{Recommendations}

Further research on contextual factors influencing prevention care for secondary health conditions in people with spinal cord injuries is needed to understand what are the barriers and facilitators to preventing SHCs. Lastly, there is a need for research on the occurrence of secondary health conditions in terms of the types of SHCs and the risk factors associated with the co-occurrence.

\section{Limitations of the study}

This study was a descriptive qualitative design, thus generalization of the findings to the SCI population will be limited. The study participants were mostly men, paraplegics and traumatic SCl. Future research 
must focus on women with $\mathrm{SCl}$ and on non-traumatic SCl. However, to the researchers' knowledge, this is the first study to listen to patients with $\mathrm{SCI}$ narratives on their experiences on experiences with secondary health conditions and the impact they have on their wellbeing in a public health care facility in South Africa.

\section{List Of Abbreviations}

SHC-Secondary health condition

SCI-Spinal cord injury

OPD-Outpatient

TB-Tuberculosis

\section{Declarations}

Ethical considerations and consent to participate

Ethical approval was obtained from the Human Research Ethics Committee (Medical) of the University of the Witwatersrand (M170938) and the study was registered with the South African National Health Research Database (reference GP201712036). Permission to use the study site for data collection was granted by the tertiary rehabilitation hospital. The study was explained to the participants as well as their rights to withdraw their participation at any stage. Interviews were conducted with patients who gave informed consent prior to the interview and permission to audio record the interview. To protect anonymity, the patients with $\mathrm{SCl}$ will be labelled using their gender, type of $\mathrm{SCl}$ and age.

Consent for publication: N/A

Availability of data: The datasets used and/or analysed during the current study are available from the corresponding author on reasonable request.

Competing interest: The authors declare that they have no competing interests

Funding: This research was supported by:

1. Consortium for Advanced Research Training in Africa (CARTA). CARTA is jointly led by the African Population and Health Research Center and the University of the Witwatersrand and funded by the Carnegie Corporation of New York (Grant No-B 8606.R02), Sida (Grant No:54100113), the DELTAS Africa Initiative (Grant No: 107768/Z/15/Z) and Deutscher Akademischer Austauschdienst (DAAD). The DELTAS Africa Initiative is an independent funding scheme of the African Academy of Sciences (AAS)'s Alliance for Accelerating Excellence in Science in Africa (AESA) and supported by the New Partnership for Africa's Development Planning and Coordinating Agency (NEPAD Agency) with 
funding from the Wellcome Trust (UK) and the UK government. The statements made and views expressed are solely the responsibility of the Fellow.

2. National Research Foundation Grant (THUTHUKA FUNDING) for research funding

Both funders played no role in the design of the study and collection, analysis, and interpretation of data and in writing the manuscript.

Author's contributions:

This study was part of the SP doctoral dissertation at the University of the Witwatersrand (South Africa).

SP-conceptualized the study, collected data, analysed data and wrote the manuscript.

HM and JP-supervision during the conceptualization phase, assisted during data analysis, read several iterations of the paper and conducted the final editing.

Acknowledgements

We are grateful to the patients with spinal cord injuries who participated in this study.

\section{References}

1. Zhang S, Wadhwa R, Haydel J, Toms J, Johnson K, Guthikonda B. Spine and Spinal Cord Trauma. Diagnosis and Management. Neurologic Clinics. 2013;31(1):183-206.

2. Musubire AK. A Systematic Review of Non-Traumatic Spinal Cord Injuries in Sub-Saharan Africa and a Proposed Diagnostic Algorithm for Resource-Limited Settings. 2017;8(December):1-12.

3. Draulans N, Kiekens C, Roels E, Peers K. Etiology of spinal cord injuries in Sub-Saharan Africa. Spinal Cord. 2011;49(12):1148-54.

4. James SL, Theadom A, Ellenbogen RG, Bannick MS, Montjoy-Venning W, Lucchesi LR, et al. Global, regional, and national burden of traumatic brain injury and spinal cord injury, 1990-2016: a systematic analysis for the Global Burden of Disease Study 2016. The Lancet Neurology. 2019 Jan 1;18(1):56-87.

5. Rahimi-Movaghar V, Sayyah MK, Akbari H, Khorramirouz R, Rasouli MR, Moradi-Lakeh M, et al. Epidemiology of traumatic spinal cord injury in developing countries: a systematic review. Neuroepidemiology. 2013;41(2):65-85.

6. Chamberlain JD, Meier S, Mader L, Von Groote PM, Brinkhof MWG. Mortality and longevity after a spinal cord injury: Systematic review and meta-analysis. Neuroepidemiology. 2015;44(3):182-98.

7. Joseph C, Delcarme A, Vlok I, Wahman K, Phillips J, Wikmar LN, et al. Incidence and aetiology of traumatic spinal cord injury in Cape Town, South Africa: a prospective, population-based study. Spinal Cord. 2015;53(9):692-6. 
8. Institute for Health Metrics and Evaluation. South Africa Health Data [Internet]. 2019. Available from: http://www.healthdata.org/south-africa

9. Pillay-van Wyk V, Msemburi W, Laubscher R, Dorrington RE, Groenewald P, Glass T, et al. Mortality trends and differentials in South Africa from 1997 to 2012: second National Burden of Disease Study. The Lancet Global Health. 2016;4(9):e642-53.

10. World Health Organization. Rehabilitation 2030 areas for action: [Internet]. 2017. p. 1-2. Available from: https://www.who.int/rehabilitation/CallForAction2.pdf?ua $=1$

11. World Health Organization. SDG 3: Ensure healthy lives and promote wellbeing for all at all ages. [Internet]. 2017 [cited 2018 Dec 3]. Available from: http://www.who.int/sdg/targets/en/

12. Simeonsson RJ, McMillen JS, Huntington GS. Secondary conditions in children with disabilities: Spina bifida as a case example. Mental Retardation and Developmental Disabilities Research Reviews. 2002;8(3):198-205.

13. Jensen MP, Truitt a R, Schomer KG, Yorkston KM, Baylor C, Molton IR. Frequency and age effects of secondary health conditions in individuals with spinal cord injury: a scoping review. Spinal cord. 2013;51(12):882-92.

14. Wahman K, Wikmar L, Chlaidze G, Joseph C. Secondary medical complications after traumatic spinal cord injury in Stockholm, Sweden: Towards developing prevention strategies. Journal of Rehabilitation Medicine. 2019;(7):513-7.

15. van Weert KCM, Schouten EJ, Hofstede J, De H Van, Holtslag HR, Berg-emons RJG Van Den. Acute phase complications following traumatic spinal cord injury in Dutch level 1 trauma centres. 2014;882-5.

16. Wannapakhe J, Arrayawichanon P, Saengsuwan J, Amatachaya S. Medical complications and falls in patients with spinal cord injury during the immediate phase after completing a rehabilitation program. The Journal of Spinal Cord Medicine. 2015;38(1):1-11.

17. Adriaansen J, Ruijs L, Koppenhagen C, Asbeck F, Snoek G, Kuppevelt D, et al. Secondary health conditions and quality of life in persons living with spinal cord injury for at least ten years. Journal of Rehabilitation Medicine. 2016;48(10):853-60.

18. Brinkhof MWG, Al-Khodairy A, Eriks-Hoogland I, Fekete C, Hinrichs T, Hund-Georgiadis M, et al. Health conditions in people with spinal cord injury: Contemporary evidence from a population-based community survey in Switzerland. Journal of Rehabilitation Medicine. 2016;48(2):197-209.

19. Muller R, Brinkhof MW, Arnet U, Hinrichs T, Landmann G, Jordan X, et al. Prevalence and associated factors of pain in the Swiss spinal cord injury population. Spinal cord. 2016/11/16. 2017;55(4):34654.

20. Craven C, Hitzig SL, Mittmann N. Impact of impairment and secondary health conditions on health preference among Canadians with chronic spinal cord injury. The journal of spinal cord medicine. 2012;35(5):361-70.

21. Callaway L, Barclay L, Mcdonald R, Farnworth L, Casey J. Secondary health conditions experienced by people with spinal cord injury within community living: Implications for a National Disability 
Insurance Scheme. Australian Occupational Therapy Journal. 2015;62(4):246-54.

22. van der Meer $P, M$ Post MW, C van Leeuwen CM, M van Kuppevelt HJ, J Smit CA, A van Asbeck FW. Impact of health problems secondary to $\mathrm{SCl}$ one and five years after first inpatient rehabilitation. 2016;55.

23. Munce SEP, Webster F, Fehlings MG, Straus SE, Jang E, Jaglal SB. Perceived facilitators and barriers to self-management in individuals with traumatic spinal cord injury: a qualitative descriptive study. 2014;1-12.

24. Guilcher SJT, Craven BC, Lemieux-Charles L, Casciaro T, McColl MA, Jaglal SB. Secondary health conditions and spinal cord injury: an uphill battle in the journey of care. Disability and Rehabilitation. 2013;35(11):894-906.

25. Fuseini A, Aniteye P, Alhassan A. Beyond the Diagnosis: Lived Experiences of Persons with Spinal Cord Injury in a Selected Town in Ghana. Neurology Research International. 2019;2019:1-10.

26. Loo MA Van, Post MWM, Bloemen JHA, Asbeck FWA Van. Care needs of persons with long-term spinal cord injury living at home in the Netherlands. Spinal Cord. 2009;48(5):423-8.

27. Joseph C, Wikmar L. Prevalence of secondary medical complications and risk factors for pressure ulcers after traumatic spinal cord injury during acute care in South Africa. Spinal Cord. 2016;54(7):535-9.

28. Mashola MK, Mothabeng DJ. Associations between health behaviour, secondary health conditions and quality of life in people with spinal cord injury. African Journal of Disability. 2019;8:1-9.

29. Mayosi BM, Ch B, Phil D, Benatar SR, Ch B, Med DS. spe ci a I re p or t Health and Health Care in South Africa-20 Years after Mandela. 2014;

30. Kleinman A, Eisenberg L, Good B. Culture, illness, and care. Clinical lessons from anthropologic and cross-cultural research. Annals of Internal Medicine. 1978;88(2):251-8.

31. Colorafi KJ, Evans B. Qualitative Descriptive Methods in Health Science Research. Health Environments Research and Design Journal. 2016;9(4):16-25.

32. Erlingsson C, Brysiewicz P. African Journal of Emergency Medicine COMMENTARY A hands-on guide to doing content analysis. 2017;7:93-9.

33. Krefting L. Rigor in qualitative research: The assessment of trustworthiness. American journal of occupational therapy. 1991;45(3):214-22.

34. Stillman MD, Barber J, Burns S, Williams S, Hoffman JM. Complications of Spinal Cord Injury Over the First Year After Discharge From Inpatient Rehabilitation. Archives of physical medicine and rehabilitation. 2017 Sep 1;98(9):1800-5.

35. Piatt JA, Nagata S, ZahI M, Li J, Rosenbluth JP. Problematic secondary health conditions among adults with spinal cord injury and its impact on social participation and daily life. J Spinal Cord Med. 2016/02/03. 2016;39(6):693-8.

36. Fuseini A-G, Aniteye P, Kofi-Helegbe G. Barriers and facilitators related to the health care system in spinal cord injury. Nursing Practice Today. 2018;5(3):335-46. 
37. Muller R, Brinkhof MW, Arnet U, Hinrichs T, Landmann G, Jordan X, et al. Prevalence and associated factors of pain in the Swiss spinal cord injury population. Spinal cord. 2016/11/16. 2017;55(4):34654.

38. Divanoglou A, Augutis M, Sveinsson T, Hultling C, Levi R. Self-reported health problems and prioritized goals in community-dwelling individuals with spinal cord injury in Sweden. Journal of Rehabilitation Medicine. 2018;50(10):872-8.

\section{Figures}

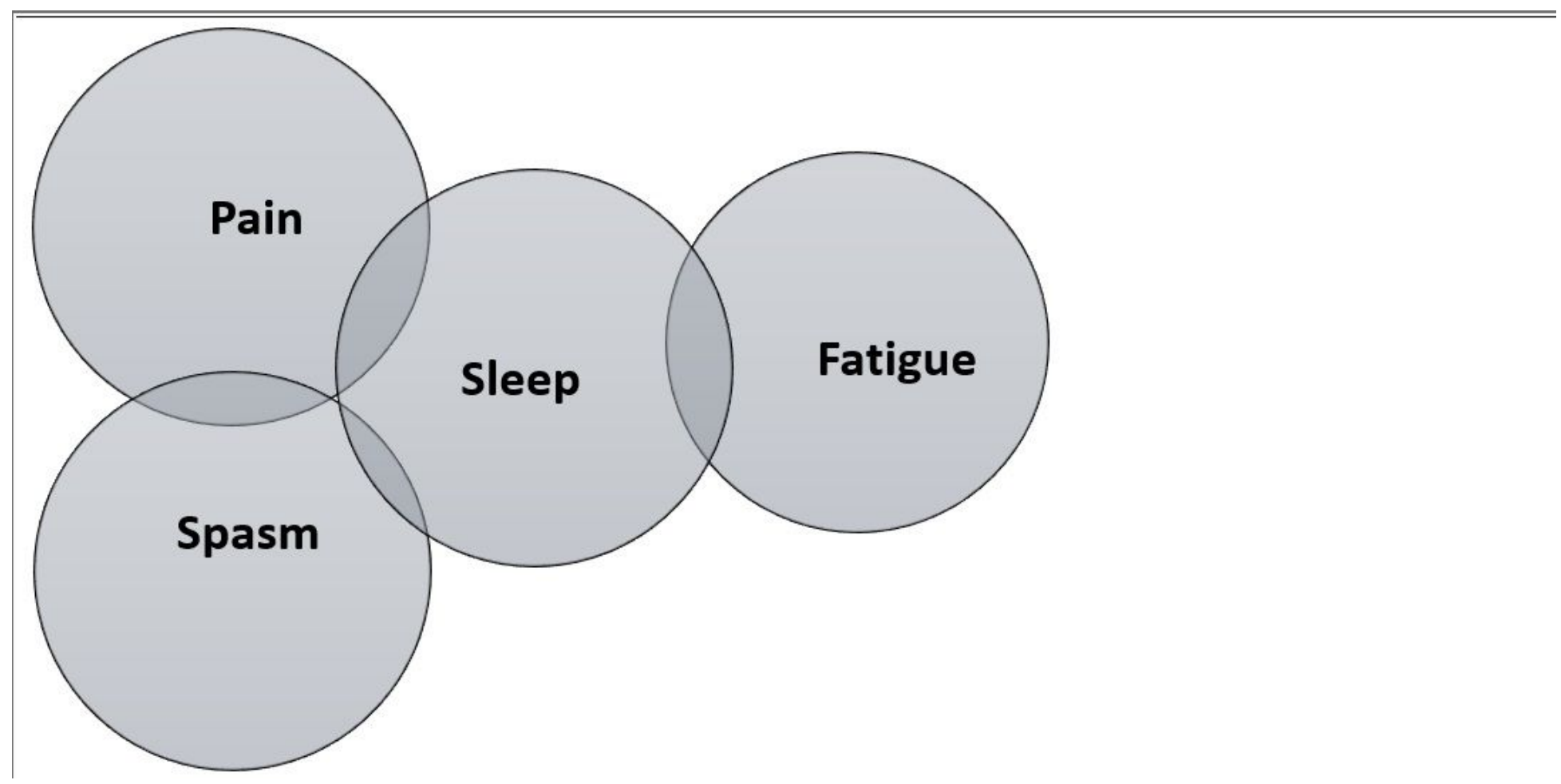

Figure 1

Co-occurrence of secondary health conditions 